\title{
Antioxidant Activity from the Enzymatic Hydrolysates of Chlorella sorokiniana and Its Potential Peptides Identification in Combination with Molecular Docking Analysis
}

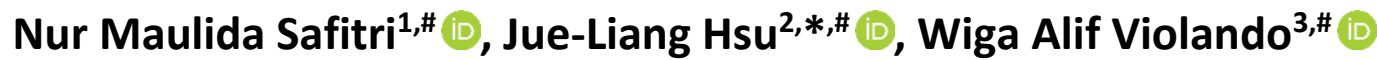 \\ ${ }^{1}$ University of Muhammadiyah Gresik, Faculty of Agriculture, Department of Aquaculture, 61121 Gresik, Indonesia. \\ ${ }^{2}$ National Pingtung University of Science and Technology, Department of Biological Science and Technology, 91201 \\ Pingtung, Taiwan, ROC. \\ ${ }^{3}$ UIN Sunan Ampel, Faculty of Science and Technology, Department of Marine Science, 60237 Surabaya, Indonesia. \\ \#These authors share the first authorship.
}

\section{How to cite}

Safitri, M.N, Hsu, J.L, Violando, W.A (2022). Antioxidant Activity from the Enzymatic Hydrolysates of Chlorella sorokiniana and Its Potential Peptides Identification in Combination with Molecular Docking Analysis. Turkish Journal of Fisheries and Aquatic Sciences, $22(4)$, TRJFAS20316. http://doi.org/10.4194/TRJFAS20316

\section{Article History}

Received 24 July 2021

Accepted 09 November 2021

First Online 11 November 2021

\section{Corresponding Author}

Tel.: +88687703202 (5197)

E-mail: jlhsu@mail.npust.edu.tw

\section{Keywords}

Bioactive peptides

Chlorella sorokiniana

DPPH assay

Molecular docking

SCX Chromatography

\begin{abstract}
Chlorella sorokiniana is an edible microalga known for its high protein content with a balanced amino acid composition, nutritional value, beneficial health effect, and natural antioxidant. The enzymatic assays was used to extract the peptides of $C$. sorokiniana which was an uncommon method to test the antioxidant activity. In this research, protein of $C$. sorokiniana was extracted, purified, and hydrolyzed in several enzymes and kept at $37^{\circ} \mathrm{C}$ for $16 \mathrm{~h}$. Hence, enzymatic hydrolysate $<3 \mathrm{kDA}$ was fractionated into 11 portions (C0\%, C10\%, to $\mathrm{C} 100 \%$ ) by using offline Strong Cation Exchange Chromatography ( $\mathrm{SCX}$ ) and their antioxidant activity was tested using DPPH (2.2-diphenyl-1-picrylhydrazyl) radical scavenging assay. The results indicated that C80\%, contributed to the highest free DPPH scavenging on C. sorokiniana hydrolysate with the inhibition of $22.04 \%$. Furthermore, to find the candidate peptides, this fraction was injected into LC-MS/MS for characterization of it's DPPH inhibitation. LSSATSAPS ( $\mathrm{m} / \mathrm{z} 1638,78)$ and AGLYGHPQTQEE $(\mathrm{m} / \mathrm{z} 1328.59)$ are peptides that were identified and confirmed by LC-MS/MS. The molecular docking study was conducted to provide the binding simulation between these peptides and the ROS1 as the receptor. In conclusion, our results suggested that the aforementioned peptides were attached to ROS1 binding site and contributed to its potential antioxidant activity.
\end{abstract}

\section{Introduction}

Nowadays, the increasing danger of global warming has become more vivid. The atmospheric $\mathrm{CO}_{2}$ and greenhouse effect are also increased significantly due to sun radiation traps in the atmosphere causing elevated temperature of the earth (Cassia et al., 2018). Therefore, to decrease the $\mathrm{CO}_{2}$ concentration, photosynthesis is required without any further physical pressure on the environment. In addition, this is more efficient and frequently occurs in microalgae than in any other terrestrial higher plant (Themaladze \& Makhashvili, 2016). However, due to the exposure of high oxygen level and light during photosynthesis, photooxidative damage was absent in microalgae (Cassia et al., 2018). This suggests that their cells possess antioxidative and protective mechanisms by preventing the injurious oxygenation of molecules from harmful agents and oxidized (Matsukawa et al., 1998).The tendency of microalgae to change their intracellular concentration in response to depressed environmental conditions has, therefore led to the possible observation of their antioxidant properties (Hosikian et al., 2010).

'Photoadaptive' response of microalgae to a strong negative effect of light intensity has been considered by increasing light-harvesting cellular performance in light- 
limiting situations (Kana et al., 1997). Furthermore, during the process of photosynthesis, energy is being extracted through a series of the enzymatic reaction and light penetration by photosynthetic pigments which include; chlorophylls, carotenoids, xanthophylls, and phycobiliproteins. The combination of these lightharvesting protein pigments are bound to the thylakoid membranes as protein-pigment complexes (Matsukawa et al., 1998). Even though microalgae have numerous pigments, their cells produced a reasonable concentration of chlorophyll (1-2\% $\mathrm{g} \mathrm{g}^{-1}$ dry weight) under normal conditions (Nwoba et al., 2020).

Chlorophyll molecules are primarily protein pigments used as colouring agent due to their resulting green colour on some wavelengths. It is non-toxic in nature and primarily known as chlorophyll $a$ and chlorophyll $b$, which have significant antioxidative properties (Oo et al., 2017). Chlorophyll is also the main photosynthetic pigment in green algal species, particularly in Chlorella sorokiniana. This microalgae is singular and tiny with plentiful chlorophyll pigments due to its photosynthetic function (Amin et al., 2018). Furthermore, it is also reported as a good protein source for protein hydrolysates and bioactive peptides production, with a total protein of more than $40 \%$ (Tejano et al., 2019).

Protein hydrolysates are intermediate products of readily digestible food. It extracts amino acids and peptides that improve its nutritional value ( $\mathrm{Wu}$ et al., 2017). Protein hydrolysates are considered to be more effective than intact proteins. Furthermore, it may also enhance and modify the physiochemical and functional foods without losing the nutritional content of proteins (Li-Chan, 2015). Thus, the synthesis of protein hydrolysates would be a promising agent for microalgal utility in nutrition and biomedicine (Morris et al., 2003).

Thus, the aim of this study was to evaluate the antioxidative activities of protein hydrolysates from $C$. sorokiniana and screened for its bioactive peptide. Four commercial enzymes were used to produce the hydrolysates, with their molecular characteristics determined. After fractionation, in vitro bioactivity and peptides identification were conducted accordingly. At last, the molecular-docking study of identified peptides and human ROS1 receptor molecules were also simulated to understand the possible mechanisms of its antioxidant activities.

\section{Materials and Methods}

\section{Preparation of Enzymatic Hydrolysates}

Crude powder of C. Sorokiniana was kindly donated by Far East Microalgae Industries, Co. Ltd. (FEMICO) corporation (Taipei, Taiwan) and stored for further use at $-20{ }^{\circ} \mathrm{C}$. The extraction process was followed (Shih et al., 2019) procedures. The cell wall of C. sorokiniana was disrupted in $1 \%$ sodium dodecyl sulfate (SDS 1:0.1; w/v) and sonicated (Branson; Terra
Universal Inc., LA, USA) for 7.5 minutes. The supernatant was filtered and lyophilized (Biobase; BK-FD10S., China) after centrifugation (SIGMA: 22001., Germany) in 4000 rpm for $10 \mathrm{~min}$. Furthermore, the lyophilized powder was diluted in $20 \%$ trichloroacetic acid (TCA) and kept for $12 \mathrm{~h}$ at $4{ }^{\circ} \mathrm{C}$. The purified protein was clarified after washing with ethanol (1:9; w/v) thus, lyophilized.

Purified protein was then hydrolyzed by four different enzymes; $\alpha$-chymotrypsin, pepsin, trypsin at 37 ${ }^{\circ} \mathrm{C}$, and thermolysin at $60{ }^{\circ} \mathrm{C}$ (Sigma Chemical Co) with enzyme/substrate of $1 / 20(\mathrm{w} / \mathrm{v})$ for each enzyme. The mixture was incubated for $16 \mathrm{~h}$. Hence, the hydrolysate was boiled at $100{ }^{\circ} \mathrm{C}$ for $10 \mathrm{~min}$, fractionated through ultrafiltration (UF) membranes with molecular weight cut off (MWCO) <3 kDA (Millipore) to gain lower molecular weight (LMW) and lyophilized.

The $<3 \mathrm{kDa}$ enzymatic hydrolysates were diluted in $5 \%$ of Acetonitrile (ACN) \& $0.2 \%$ of Formic Acid (FA), and fractionated using Strong Cation Exchange Chromatography (SCX-Chromatography) LSPO1-1A Longer Pump (Halma Ltd., USA). The mobile phases of buffer $A$ and $B$ were $5 \% A C N$ and $0.2 \%$ FA and $5 \%$ ACN and $0.2 \% \mathrm{FA}+0.5 \mathrm{M} \mathrm{NaCl}$, respectively. Furthermore, $1 \mathrm{mg} / \mathrm{mL}$ samples were dissolved in buffer $A$ and loaded into SCX-Chromatography with a steady flow rate of $36.6 \mu \mathrm{l} / \mathrm{min}$. Each enzymatic hydrolysate then was separated into 11 fractions according to \% buffer $B$, including; $0 \% \mathrm{~B}, 10 \% \mathrm{~B}$, to $100 \% \mathrm{~B}$. These fractions were lyophilized, desalted, and maintained at $-20{ }^{\circ} \mathrm{C}$ for further study.

\section{Measurement of Antioxidant Activities}

The antioxidant activity of $C$. sorokiniana hydrolysate was measured according to our previous research (Safitri et al., 2017). $750 \mu \mathrm{g} / \mathrm{mL}$ of enzymatic hydrolysates and $68 \mu \mathrm{g} / \mathrm{mL}$ of SCX fractions were prepared for DPPH (2.2-diphenyl-1-picrylhydrazyl) assay. Hence, $50 \mu \mathrm{L}$ of test sample was added to $150 \mu \mathrm{L}$ of DPPH diluted in methanol. The solution was mixed for 30 seconds and incubated at $25^{\circ} \mathrm{C}$ for $90 \mathrm{~min}$. Furthermore, absorption was estimated at $517 \mathrm{~nm}$ with butylated hydroxytoluene (BHT) $250 \mu \mathrm{M}$ as the standard. Moreover, methanol was used as blank and the radical scavenging capacity was estimated by this equation;

$$
\% \text { inhibition }=\frac{[(A c-A b)-(A s-A b)]}{A c-A b} \times 100 \%
$$

Where Ac, Ab and As are the absorbance of the control, the blank and the sample respectively.

\section{Identification of Bioactive Peptide Sequences}

Amino acid sequences from the active fraction of C. sorokiniana were identified using Liquid Chromatography-Tandem Mass Spectrometry (LCMS/MS) analysis (Thermo LCQ DECA XP MAX system, 
Thermo Scientific Inc., USA) with an electrospray ionization (ESI) source. The sample was dissolved in $5 \%$ ACN \& $0.2 \%$ FA and loaded into the LC symmetry C18 column $(150 \times 2.1$, particle size $5 \mu \mathrm{m}$, Thermo Scientific Inc., USA). Furthermore, peptides were determined by their charges $(+1,+2,+3)$ in the mass spectrum and were automatically selected for fragmentation by tandem MS spectra (Priyanto et al., 2015).

Furthermore, the MS/MS spectra were forwarded to Mascot Distiller v2.3.2.0 (Matrix Science, London, UK) for the purpose of identifying some potential bioactive peptide sequences. The search parameter was identified as follows: Homemade database of Chlorella sorokiniana was produced after its FASTA format was downloaded from National Center for Biotechnologi Information (NCBI) database. "Thermolysin" was the the preferred protease used for hydrolysis process. The charged peptide was $1+, 2+, 3+$ without any variable modification with 1 missed cleavage; The MS/MS tolerances were fixed at 2 and $1 \mathrm{Da}$, respectively.

\section{In Silico Study}

The crystal structure of the human ROS1 Kinase Domain in Complex with Crizotinib (PDB ID: 3ZBF) was received from Protein Data Bank. Co-crystal ligands, water and ions were removed. The chemical structure of peptides was constructed by Discovery Studio Visualizer v.16.1.0.15350. Furthermore, the peptides were docked individually and the best poses interaction was analyzed based on the lowest binding energy. However, the binding poses, hydrogen bonding, and Cation-Piinteraction between ACE residues and peptide were established by PyRx and Autodock Vina version 0.8. The binding site residues of ROS1 were retrieved from (Kumar et al., 2017) with some modifications. In total, 8 amino acid residues, including; LEU1951, ALA1978, LEU2026, GLU2027, LEU2028, MET2029, GLY2032, ARG2083, LEU2086 were used to classified out the interaction between peptides and ROS1 molecule.

\section{Statistical Analysis}

All data were carried out in triplicate and analyzed by one way ANOVA using SPSS v16.0 (Chicago, SPSS Inc). More so, data were presented as mean \pm standard error $(n=3)$. Mean was analyzed by applying Duncan's multiple range test to examine the homogeneity of variance using the same software. The graph drawn by Differences were considered significant in $p<0.05$.

\section{Result and Discussion}

\section{DPPH Inhibitory Activities of $C$. sorokiniana Enzymatic Hydrolysates}

Excessive production of hydroxyl radicals $\left(\mathrm{OH}^{*}\right)$ and other reactive oxygen species (ROS) in the living system produces oxidative damage caused by the response of these organisms to certain biomolecules. In addition, numerous studies on the assessment of the antioxidative activity of microalgae have also concluded

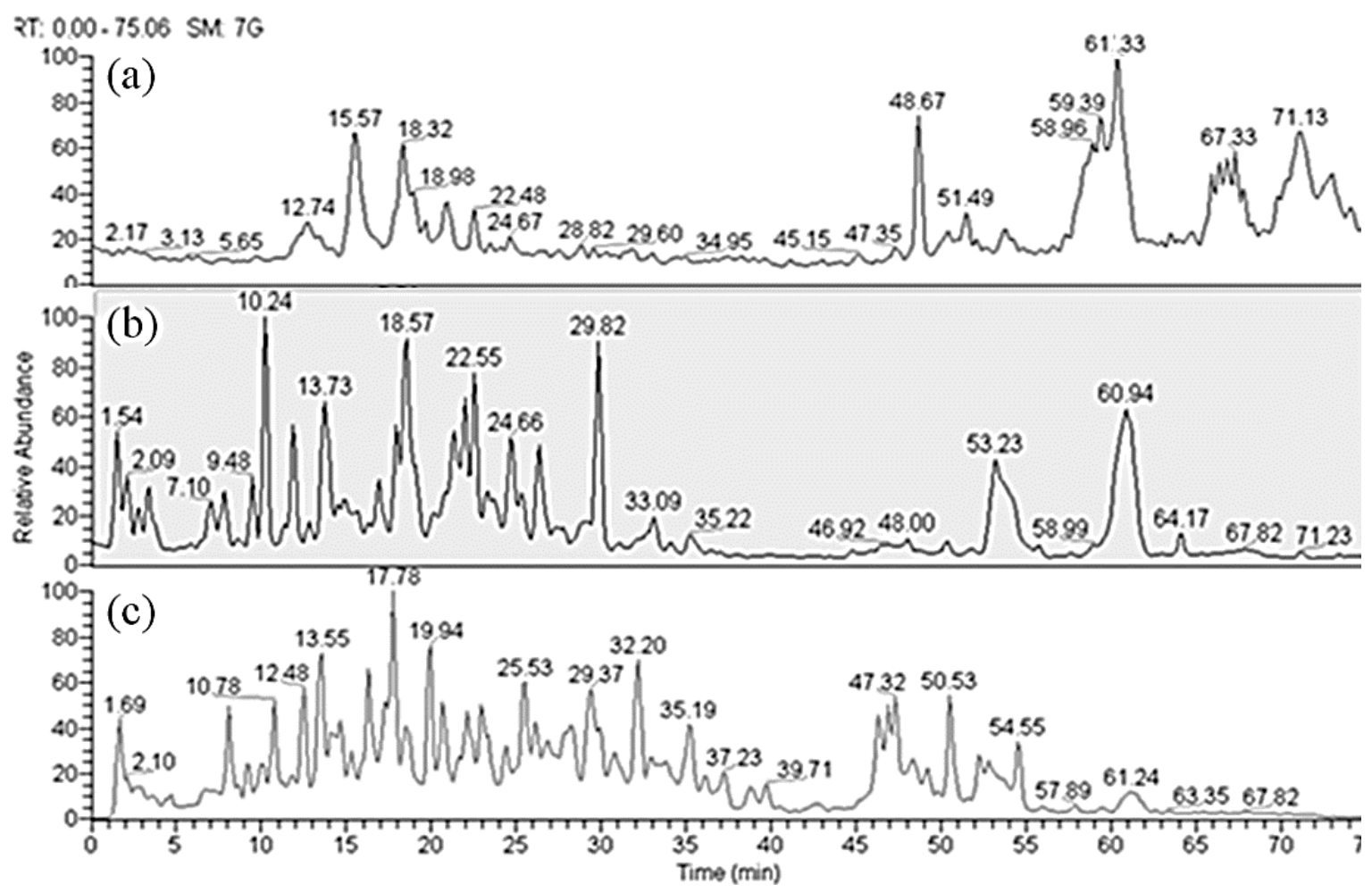

Figure 1. The potential peptides profiles using LC-MS/MS from C. sorokiniana crude protein (a); after digested with trypsin (b); after digested with trypsin LMW $<3 \mathrm{kDa}$. 
that a significant number of microalgae organisms contain various antioxidant substances including pigments, carotenoids, polyunsaturated fatty acids, polysaccharides, or bioactive peptides (Li et al., 2007; Rao et al., 2006). These compounds are well defined as radical scavengers because their ability as hydrogen atoms or electrons donors, preparing a formation of stable intermediate radicals. They were also able to stop the development of iron-mediated oxyradicals, prevent multiple oxidative stress pathways, considering the origin of tremendous health problems (Jomova \& Valko, 2011)

C. sorokiniana has attracted an increasing interest due to its biological activity (Tejano et al., 2019). This photosynthetic microalgae has been identified as a high content of protein, the green pigment, and other nutrients on a dry weight basis (Petruk et al., 2018). To gained the crude protein, $C$. sorokiniana was extracted using TCA-acetone method. Thus, the high molecular weight of $C$. sorokiniana protein was cut into lower molecular weight $(<3 \mathrm{kDa})$ through ultrafiltration membranes due to its higher bioactivity. In addition, it was hydrolyzed using trypsin to primarily identify the potential peptides peaks, as seen in Figure 1. Each purification step indicated peptides more clearly. However, Figure 1c showed that more peptides were characterized by $<3$ kDa tryptic enzymatic hydrolysates than extracts without UF membrane (Figure 1b) or crude protein (Figure 1a).

Trichloroacetic acid (TCA) extraction method with additional centrifugation were capable of increasing the antioxidant capacity of $C$. sorokiniana. Furthermore, protein fraction treated with TCA and centrifuged once in C. vulgaris had a higher radical scavenging activity than when untreated with TCA and separated to $5 \mathrm{kDa}$; in concentration $0.2 \mathrm{mg} / \mathrm{mL}$. The antioxidant capacity was enhanced significantly after treating with TCA precipitation, single centrifugation, and separated to $<5$ $\mathrm{kDa}$ filter, with the inhibition activity $11.1 \%$ at a concentration of $1 \mathrm{mg} / \mathrm{mL}$ (Zielinski et al., 2020).

Several proteases, such as pepsin, trypsin, $\alpha$ chymotrypsin, and thermolysin were added and tested for their potential DPPH inhibition. Furthermore, the lyophilized sample of $C$. sorokiniana enzymatic hydrolysates was examined for its DPPH-free radical scavenging activity. Even though, in our experiments, protein hydrolysates were prepared with the higher concentration than $\mathrm{BHT}$, all remaining samples of $C$. sorokiniana enzymatic hydrolysates exhibited a lower scavenging capacity of DPPH free radical. As seen in Figure 2, each enzymatic hydrolysate possessed a strong DPPH inhibition which was recorded as follows: Pepsin 9.17 $\pm 3.9 \%$; trypsin $14.46 \pm 1 \%$; chymotrypsin $15.66 \pm 2 \%$; and thermolysin $16.91 \pm 3 \%$. At lower concentrations, BHT (as the positive control) inhibited DPPH in $90.9 \pm 0.45 \%$. Similar to our results, research conducted by Martel et al (2017) suggested that crude phenolic extracts of cyanobacteria and microalgae strains prepared at $1-40 \mathrm{mg} / \mathrm{mL}$ demonstrated DPPH scavenging activity when the samples were prepared at a higher concentration than the solutions of $\mathrm{BHT}$, the most commonly used food synthetic preservatives.

In general, the scavenging activity of ultrafiltrated hydrolysate was considerably higher, hence, indicated by the improved resistance to oxidation by enzymatic hydrolysis. Therefore, in this study, C. sorokiniana extract was specifically hydrolyzed with multiple proteolytic enzymes and filtrated to molecular weight cut off $<3 \mathrm{kDa}$. More so, it was recorded in several experiments that the lower molecular weight exhibits

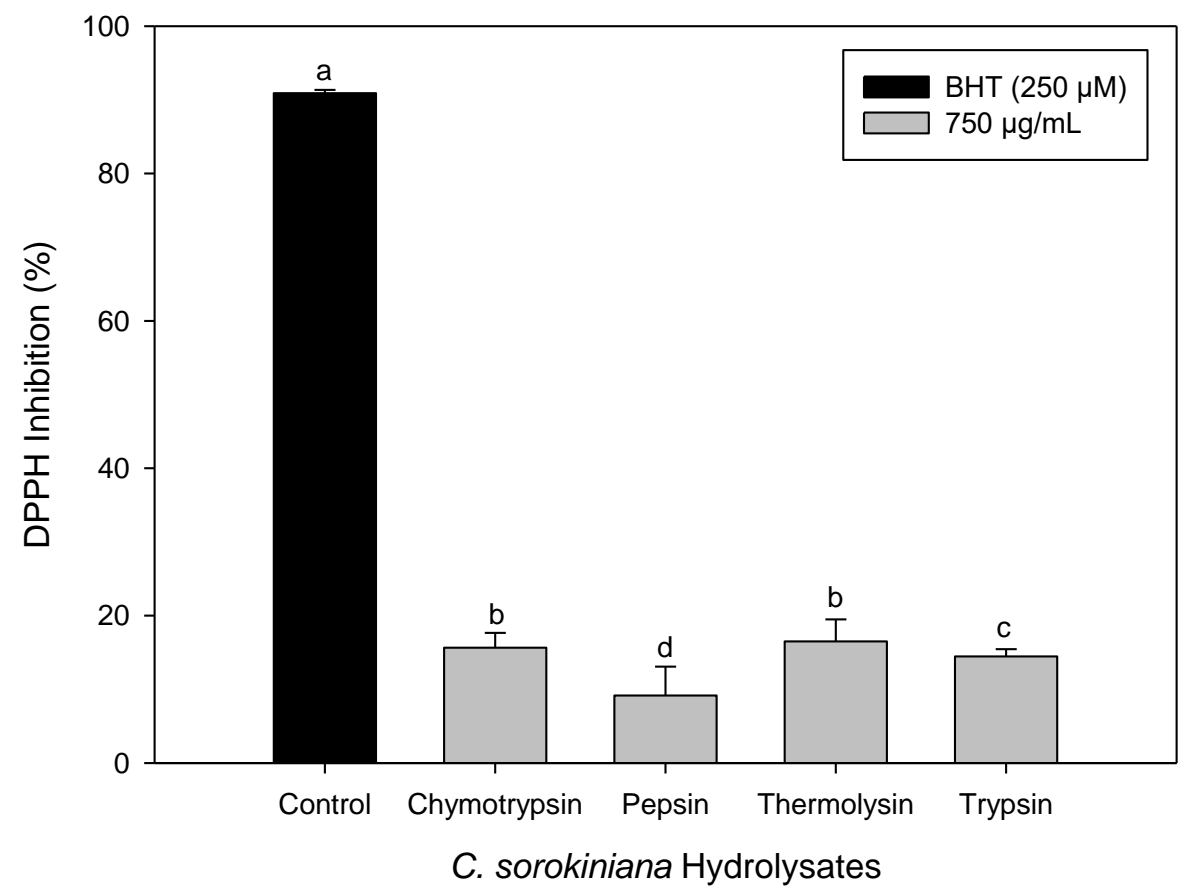

Figure 2. The DPPH inhibitory activities of $C$. sorokiniana enzymatic hydrolysates were collected from ELISA reader 
higher free-radical scavenging capacity due to its abundant amino acid residues for the donation of electrons to DPPH radicals. However, peptide $<3 \mathrm{kDa}$ from natural protein hydrolysates demonstrated the highest antioxidant activity over above $10 \mathrm{kDa}$ to 100 kDa (Chi et al., 2015; Ngoh \& Gan, 2016; Zhang et al., 2011).

\section{Hydrolysates Separation Using Offline SCX Chromatography}

SCX chromatography is a kind of cation exchange chromatography that is widely used to fractionate proteins and peptides based on their charges. Salt and the positively charged peptide will bind to the SCX column, while the negatively charged peptides will not retain (Zhu et al., 2017). Furthermore, the $<3 \mathrm{kDa}$ of thermolytic hydrolysates were directly injected into the chromatography and the collected fractions were desalted to remove any salt; either from sample or buffer. However, it is shown in Figure 3 that this hydrolysate was further separated into eleven fractions, with the inhibition from $0.78 \pm 0.1 \%$ to $22.04 \pm 0.6 \%$. Among them, $80 \%$ fraction from C. sorokiniana thermolytic hydrolysates were found to be effective against DPPH-free radical scavenging (Figure 3).

\section{Identification of DPPH Inhibitory Peptides using LC- MS/MS and Database-Assisted Sequencing}

After finding the most active fraction, characters of the peptides were defined further using LC-MS/MS. The scan range was from $100-1600 \mathrm{~m} / \mathrm{z}$ with the charged number ranging from +1 to +4 . Furthermore, the raw data were transformed into MGF files and processed using mascot distiller database to identify DPPH inhibitory peptides via database searching. Two peptides were indicated in fraction $\mathrm{C} 80 \%$ with their double charged at $\mathrm{m} / \mathrm{z} 409.695$ and $\mathrm{m} / \mathrm{z} 664.295$ (Table 1). However, based on the Mascot distiller database

Table 1. Identified peptides on C80\% offline SCX fractions by Mascot distiller database search

\begin{tabular}{|c|c|c|c|c|c|c|}
\hline Fractions & Identified Protein & Identified Peptide & Observed m/z & $\begin{array}{c}\text { Charge } \\
\text { number (z) }\end{array}$ & $\begin{array}{c}\text { Peptide } \\
\text { mass (calc) }\end{array}$ & $\begin{array}{l}\text { Identitiy } \\
\text { MASCOT } \\
\text { score of } \\
\text { peptide }\end{array}$ \\
\hline C80\% & $\begin{array}{l}\text { Photosystem I P700 } \\
\text { chlorophyll-a } \\
\text { apoprotein A2 } \\
\text { (chloroplast) }\end{array}$ & LSSATSAPS (LS9) & 409.695 & 2 & 819.39 & $23 / 26$ \\
\hline C80\% & $\begin{array}{l}\text { DNA-directed RNA } \\
\text { polymerase subunit } \\
\text { (chloroplast) }\end{array}$ & AGLYGHPQTQEE (AE12) & 664.295 & 2 & 1328.59 & $21 / 22$ \\
\hline
\end{tabular}

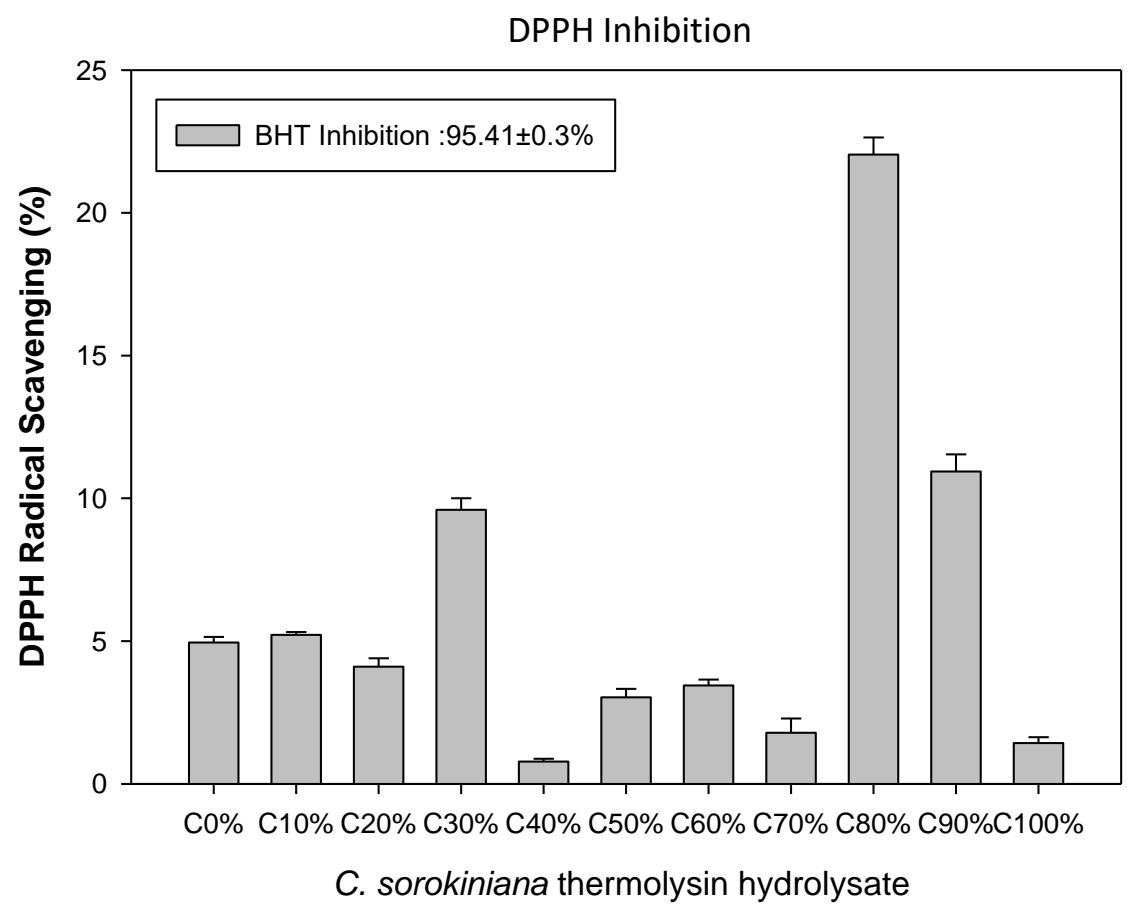

Figure 3. The DPPH inhibitory activities of $C$. sorokiniana thermolytic fractions using SCX chromatography. 
search, it's seen in Figure 4 that these two peptides were identified as LSSATSAPS (LS9) (Fig.4b) and AGLYGHPQTQEE (AE12) (Figure 4c). They were identified by LC/MS at retention time (RT) 45.63 (LS9) and 49.80 (AE12), while the peak at RT 1.57 (Figure 4a) was confirmed as solvents.

Under stress conditions, microalgae usually build defense mechanisms to prevent their cells from any cellular damages. Major secondary metabolites were increased during this process to stabilize their metabolisms. However, research conducted by Shanab et al. (2012) explained a noticeable increase in phycobilin pigments of several microalgae including $C$. vulgaris. This enhancement was followed by an increase in antioxidant activities (60-66.8\%) in several species tested than its control (59.8\%).

C. sorokiniana has been produced without any difficulties. In high biomass yields under over-saturating light conditions and that led to the use of chloroplasts for photosynthesis in a long time (Cuaresma et al., 2018). Furthermore, several photosynthetic molecules including chlorophylls are specifically organized around pigment-protein complexes called photosystems and are fixed in the thylakoid membranes of the chloroplast. Photosystem I (PSI) consists of two subdivisions which are; a core complex responsible for the separation of charges and light-harvesting antenna complexes that have responsibilities to increase the detection of light energy and its transmission to the reaction center in the central complex (Brotosudarmo et al., 2018). Moreover, chloroplasts possess their genomes (DNA), the stroma comprises chloroplast DNA (cpDNA), special ribosomes, and genes for the RNA subunits (Antolin \& Black, 2018).
Consequently, it indicated that the major protein in this research was enclosed in the chloroplast protein. According to the NCBI database, 734 (81.76 kDa) and 1417 (161.6 kDa) amino acids sequence were found from Photosystem I P700 chlorophyll-a apoprotein and DNA-directed RNA polymerase subunit beta in Chlorella sorokiniana protein.

Research conducted by Petruk et al (2018) suggested that chlorophyll c2 (609.3 Da), hydroxylated chlorophyll-a (908.9 Da), and pheophytin (871.2 Da) were detected as the active fractions contributed to antioxidants molecules of $C$. sorokiniana extract, which was detected by LC-TOF and confirmed by tandem MS, and similar to our results. Nevertheless, another research by Lai and Sun (2017) concluded that the antioxidant ingredients characterized in ethanol extract of $C$. sorokiniana were majorly polyunsaturated fatty aid, fatty alcohols, or phytols; which was identified in $\lambda_{\mathrm{nm}}: 278-281 \mathrm{~nm}$.

\section{In Silico Analysis}

As an antioxidative peptide, the potential antioxidant peptide is heavily determined by its amino acid sequence, especially when its containing aromatic and hydrophobic amino acids, caused by the existence of an imidazole/indole/pyrrolidine ring as an effective donor of the proton to create more stable products and prevent the radical chain reaction (Torres-Fuentes et al., 2015; Zou et al., 2016). Furthermore, Figure 5a showed that peptide LS9 from $C$. sorokiniana thermolytic hydrolysate in our study contained several hydrophobic amino acids, including leucine, alanine, proline, and

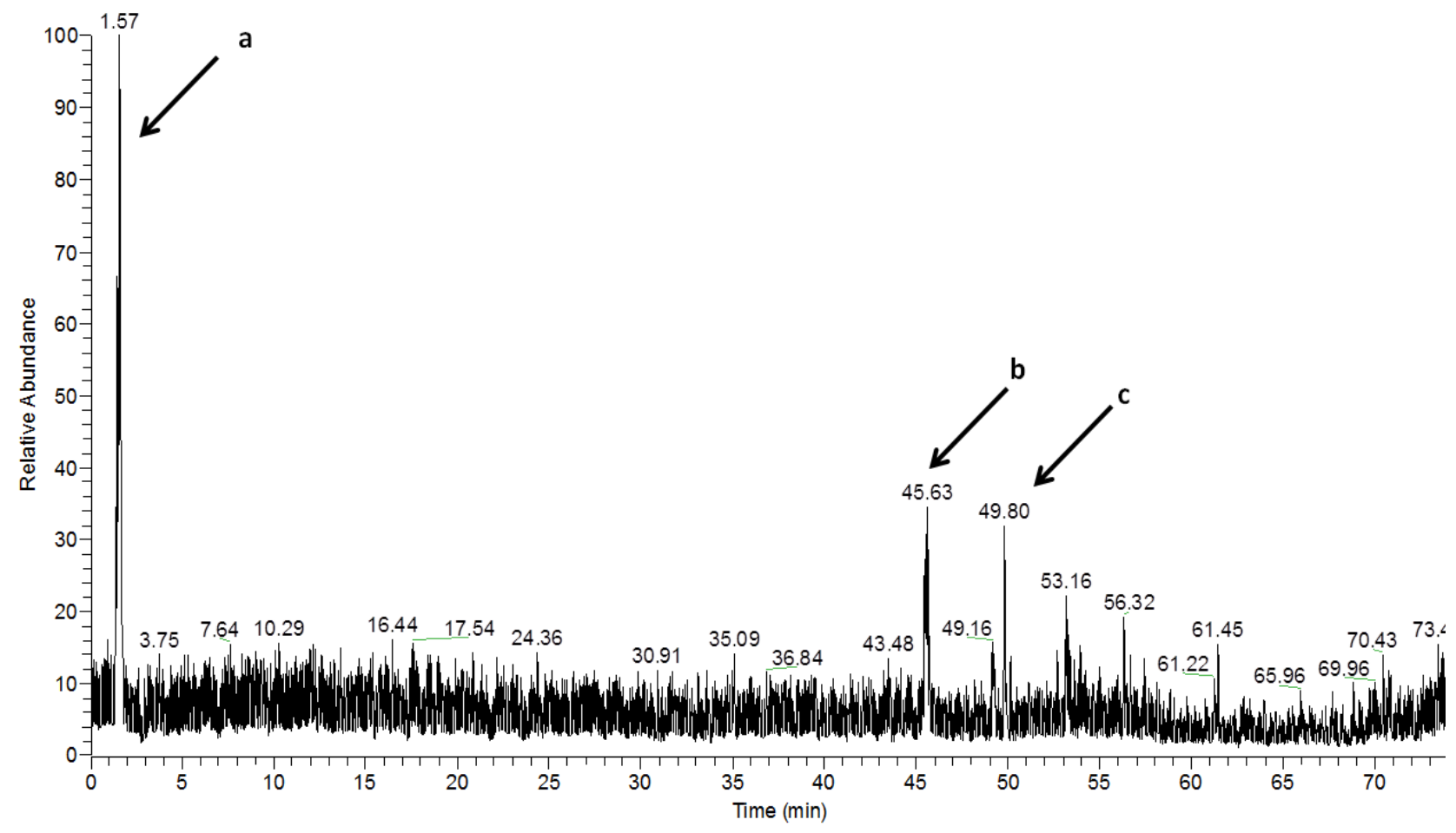

Figure 4. (a) LC-MS chromatogram of solvents; (b) LSSATSAPS (LS9); and (c) AGLYGHPQTQEE (AE12). 
threonine. The last two aforementioned acids have unique structure including pyrrolidine ring (proline) and indole ring (threonine). Moreover, more hydrophobic amino acids were found on AE12 peptide (Figure 5b). Several hydrophobic amino acids were established in line at the $\mathrm{N}$-terminal position, including alanineglycine-leucine-tyrosine-glycine-histidine-proline.

Another indole ring threonine was also found in these sequences. Other amino acid sequences tended to hydrophilic.
The in silico results are shown in Figure 6 . Hydrogen bonds are displayed by dashed lines among the atoms involved, while the hydrophobic and contacted atoms are delineated shown with spokes radiating, facing the contacted ligand atoms. More so, the binding affinities of LS9 and AE12 peptides to ROS1 crizotinib complex resolution by Autodock were -6.4 and -6 kcal/mol, respectively. Peptides interacted consistently on the binding region of the ROS1 receptor (Figure 6a, Figure 6b).

(a)<smiles>COC(=O)C(CO)NC(=O)C1CCCN1C(=O)C(C)NC(=O)C(CO)NC(=O)C(NC(=O)C(C)NC(=O)C(CO)NC(=O)C(CO)NC(=O)C(N)CC(C)C)C(C)O</smiles>

(b)<smiles></smiles>

Figure 5. Peptide structure of (a) LSSATSAPS (LS9) and (b) AGLYGHPQTQEE (AE12)

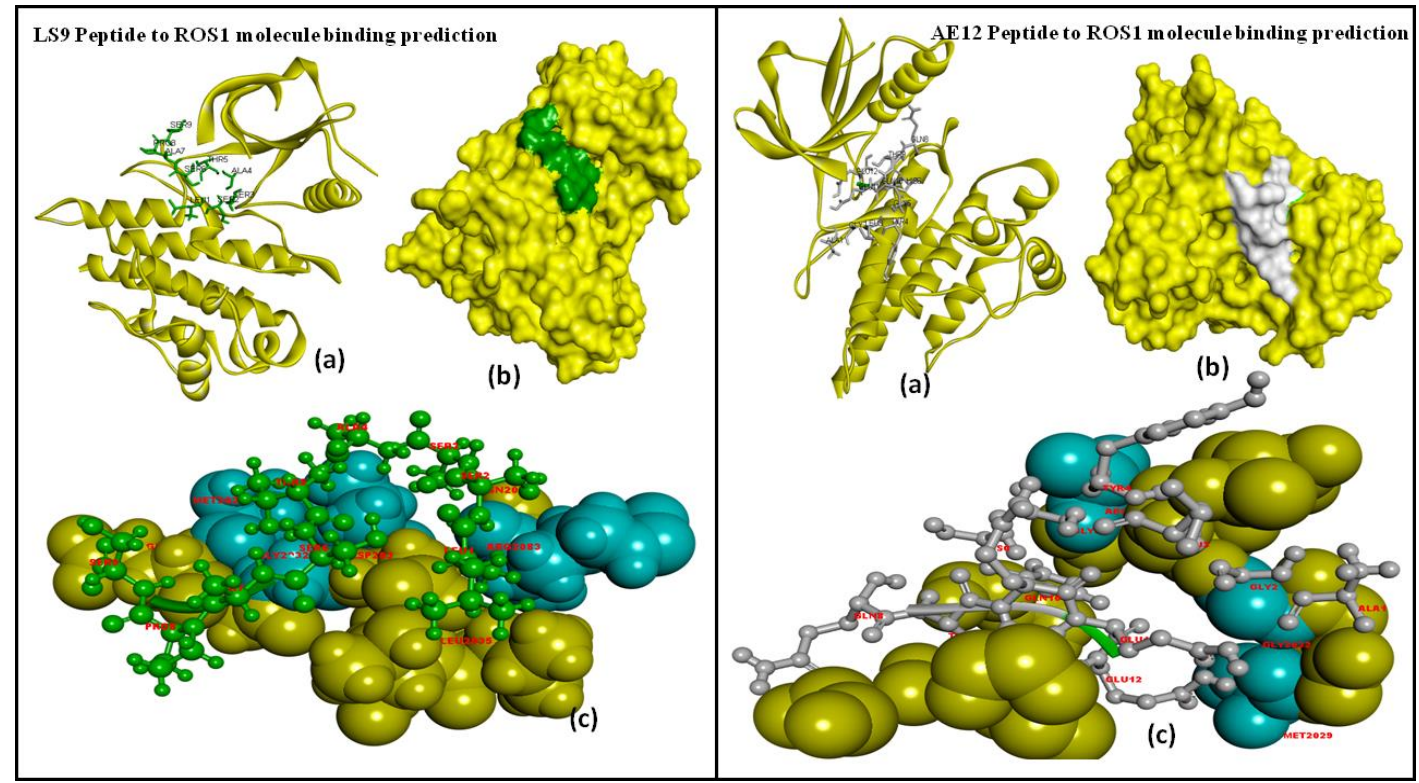

Figure 6. Molecular modeling of LS9 (left, green color) and AE12 (right, grey color) binding to ROS1 (PDB Code: 3ZBF). The receptor was shown as yellow ribbon and balls; the active site of the receptor was represented as blue balls, respectively. (a) The threedimensional model of peptides binding with ROS1 receptor, shown in ribbon and stick; (b) in surface representation; (c) The binding prediction of the peptide with ROS1 active site. 
LS9 was predicted to have bonded 9 residues: E2030, D2033, L2035, L2036, N2083, and ROS1 binding residues M2029, G2032, R2083, and L2086. Conversely, $A E 12$ was predicted to have bonded more residues than LS9, including G1952, G1957, V1959, K1980, E2030, G2031, D2033, T2036, Y2037, N2084, V2087, I2100, G2101, D2102, and F2103. Even though the sequence was longer, AE12 was only bonded to 2 active site residues of ROS1, including M2029 and G2083. The RMSD of LS9 was $-0.21 \mathrm{~nm}$ while the AE12 structure attained an RMSD of $-0.33 \mathrm{~nm}$. However, our dynamic simulation study showed that the bonding region between peptides-ROS1 receptor in LS9 was dominated by hydrophilic amino acids; proline did not interact with any ROS-1 binding region, and each serine residues was interacted and bonded to ROS1 receptor. Conversely, the whole residues of $A E 12$ peptide interacted with ROS1 structure residues (Figure 6c).

Another computational bonding mode to ROS1 was designed by Luo et al (2017). Furthermore, Mitoxantrone is an authorized FDA drug for hormonerefractory prostate cancer, multiple sclerosis, and it is highlighted as a significant inhibitor of the ROS1 fusion protein. This drug is capable of suppressing ROS1 phosphorylation and stopping its downstream signaling cascade, thus, inducing cell apoptosis. More so, the in silico molecular docking showed overlapped mitoxantrone with the crizotinib position; this substance was docked and buried in a hydrophobic pocket comprised of various amino acids such as; L1951, V1959, L2010, L2026, E2027, M2029, D2033, D2083, L2086, and K2090.

To understand the bonding mechanisms of $C$. sorokiniana extracts to ROS1, Napolitano et al (2020) conducted an in vivo research on an experiment by using crude $C$. sorokiniana consumption on hyperthyroid rat livers. In this experiment, their food consumption was able to protect cells from oxidative injuries and cancel out an oxidative attack in vivo. However, this microalgae was able to interfere with cellular ROS development and the removal processes of cellular ROS; reducing the rate of oxidative risk markers and increase its antioxidant capacities (Napolitano et al., 2020). Thus, further research using in vitro and in vivo analysis is needed to understand the free-radical scavenging activity of $C$. sorokiniana fractions and peptides against ROS1, hence, increase its antioxidant activity.

\section{Conclusions}

It was confirmed that $C$. sorokiniana have demonstrated antioxidative activities through freeradical scavenging and counteracting oxidative stress. However, the antioxidative activities were mainly due to high protein contents inside the cells. Thus, the protein was extracted, purified, and hydrolyzed using several enzymes. The active peptides that contributed to its inhibition were identified as LSSATSAPS (LS9) with $\mathrm{m} / \mathrm{z}$ 1638.78 and AGLYGHPQTQEE (AE12) with $\mathrm{m} / \mathrm{z}$ 1328.59, hence, confirmed as chloroplast protein of $C$. sorokiniana. These peptides were gotten from a C80\% fraction of $C$. sorokiniana thermolytic hydrolysates by SCX chromatography. Moreover, using in silico approach, these peptides were predicted to bond several bonding residues of ROS1 crizotinib complex and induced oxidative improvements of cells, recommending its potential to be commonly advertised as an antioxidant medication.

\section{Ethical Statement}

Not applicable.

\section{Funding Information}

No funding was received to assist with the preparation of this manuscript.

\section{Author Contribution}

NMS: Methodology; Investigation; Analysis; Original Draft. JLH: Conceptualization; Analysis; Investigation; Supervision. WAV: Investigation; Writing review \& editing.

\section{Conflict of Interest}

The author(s) declare that they have no known competing financial or non-financial, professional, or personal conflicts that could have appeared to influence the work reported in this paper.

\section{Acknowledgements}

This work was supported by the Department of Biological Science and Technology, National Pingtung University of Science and Technology (NPUST), Taiwan.

\section{References}

Amin, M., Chetpattananondh, P., Khan, M., Mushtaq, F., \& Sami, S. (2018). Extraction and quantification of chlorophyll from microalgae Chlorella sp. IOP Conference Series: Materials Science and Engineering, 414(1), 12-25. https://doi.org/DOI:10.1088/1757-899X/414/1/012025

Antolin, M., \& Black, W. (2018). Genes, description. In S. Levin (Ed.), Enxyclopedia of Bioediversity.

Brotosudarmo, T., Limantara, L., Chandara, R., \& Heriyanto. (2018). Chloroplast pigments: structure, function, assembly and characteristization. In H. Ratnadewi D (Ed.), Plant Growth and Regulation - Alterations to Sustain Unfavorable Conditions. IntechOpen. https://doi.org/DOI: 10.5772/intechopen.75672.

Cassia, R., Nocioni, M., Aragunde, N., \& Lamattina, L. (2018). Climate change and the impact of greenhouse gasses: $\mathrm{CO}_{2}$ and $\mathrm{NO}$, friends and foes of plant oxidative stress. Frontiers in Plant Science, 9(273), 1-11. https://doi.org/DOI: 10.3389/fpls.2018.00273

Chi, C., Wang, B., Hu, F., Wang, Y., Zhang, B., Deng, S., \& Wu, C. (2015). Purification and identification of three novel 
antioxidant peptides from protein hydrolusate of bluefin leatherjacket (Navodon septentrionalis) skin. Food Research Internationals, 3, 124-129. https://doi.org/doi.org/10.1016/j.foodres.2014.08.038

Cuaresma, M., Janssen, M., Vilchez, C., \& Wijffels. (2018). Productivity of Chlorella sorokiniana in a short light-path (SLP) panel photobioreactor under high irradiance. Biotechnology and Bioengineering, 104(2), 352-359. https://doi.org/doi.org/10.1002/bit.22394

Hosikian, A., Lim, S., Halim, R., \& Danquah, M. (2010). Chlorophyll extraction from microalgae: a review on the engineering aspects. Bioprocess Develompent for Biofuels and Bioproducts, 1-11. https://doi.org/doi.org/10.1155/2010/391632

Jomova, K., \& Valko, M. (2011). Importance of iron chelation in free radical-induced oxidative stress and human disease. Current Pharmaceutical Design, 17(31), 34603473. https://doi.org/DOI: 10.2174/138161211798072463

Kana, T., Geider, R., \& Critchley, C. (1997). Regulation of photosynthetic pigments ini micro-algae by multiple environmental factors: a dynamic balance hypothesis. New Phytol, 137, 629-638.

https://doi.org/doi.org/10.1046/j.14698137.1997.00857.x

Kumar, A., Shanti, V., \& Ramanathan, K. (2017). Structural and functional impact of G2032R mutation in ROS1 - a theoretical perspective. Asian Journal of Pharmaceutical and Clinical Research, 10(5), 339-344. https://doi.org/doi.org/10.22159/ajpcr.2017.v10i5.176 61

Lai, P., \& Sun, T. (2017). Optimizing extraction process and characterization of antioxidant ingredients from Chlorella sorokiniana. MOJ Food Processing \& Technology, 5(1), 202-210. https://doi.org/DOI: 10.15406/mojfpt.2017.05.00114

Li-Chan, E. (2015). Bioactive peptides and protein hydrolysates: research trends and challenges for application as nutraceuticals and functional food ingredients. Current Opinion in Food Science, 1, 28-37. https://doi.org/doi.org/10.1016/j.foodchem.2006.06.02 2

Li, B., Cheng, K., Wong, C., Fan, K., Chen, F., \& Jiang, Y. (2007). Evaluation of antioxidant capacity and total phenolic content of different fractions of selected microalgae. Food Chemistry, 102(3), 771-776. https://doi.org/https://doi.org/10.1016/j.cofs.2014.09. 005

Luo, L., Fam, X., Li, Y., Peng, X., Ji, Y., Hsiao, W., Liu, L., Leung, E., \& Yao, X. (2017). Identification of mitoxantrone as a new inhibitor of ROS1fusion protein in non-small cell lung cancer cells. Medchemcomm, 8(3), 621-624. https://doi.org/DOI: 10.1039/c6md00643d

Martel, I., Garcia-Poza, S., Rodriguez-Martel, G., Rico, M., Afonso-Olivares, C., \& Gomez-Pinchetti, J. (2017). Phenolic profile and antioxidant activity of crude extracts from microalgae and cyanobacteria strains. Journal of Food Quality, 1-9. https://doi.org/doi.org/10.1155/2017/2924508

Matsukawa, R., Wada, Y., Tan, N., Sakai, N., Chihara, M., \& Karube, I. (1998). Antioxidant activity of $\mathrm{CO}_{2}$ fixing microalgae. In Studies in Surface Science and Catalysis (pp. 641-644). Elsevier Science. https://doi.org/doi.org/10.1023/A:1008141414115
Morris, H., Carrillo, O., Almarales, A., Bermudez, R., Alonso, M., Borges, L., Quintana, M., Fontaine, R., Liaurado, G., \& Hernandez, M. (2003). Protein hydrolysates from the alga Chlorella vulgaris $87 / 1$ with potentialities in immunonutrition. Biotecnología Aplicada, 26(2), 162165.

Napolitano, G., Fasciolo, G., Salbitani, G., \& Venditti, P. (2020). Chlorella sorokiniana dietary supplementation increases antioxidant capacities and reduces ROS release in mitochondria of hyperthyroid rat liver. Antioxidants (Basel), 883(9), 1-18.

https://doi.org/doi.org/10.3390/antiox9090883

Ngoh, Y., \& Gan, C. (2016). Enzyme-assisted extraction and identification of antioxidant and $\alpha$-amylase inhibitory peptides from pinto beans (Phaseolus vulgaris cv. Pinto). Food Chemistry, 190, 331-337. https://doi.org/DOI:10.1016/j.foodchem.2015.05.120

Nwoba, E., Ogbonna, C., Ishika, T., \& Vadiveloo, A. (2020). Microalgal pigments: a source of natural food colors. In Microalgae biotechnology for food, health and high value products (pp. 81-85). Springer. https://doi.org/DOI:10.1007/978-981-15-0169-2_3

Oo, Y., Su, M., \& Kyaw, K. (2017). Extraction and determination of chlorophyll content from microalgae. International Journal of Advanced Research and Publications, 1(5), 424-435.

Petruk, G., Gifuni, I., Illiano, A., Roxo, M., Pinto, G., Amoresano, A., Marzocchella, A., Piccoli, R., Wink, M., Olivieri, G., \& Monti, D. (2018). Simultaneous production of antioxidants and starch from the microalga Chlorella sorokiniana. Algal Research, 34, 164-174. https://doi.org/DOI:10.1016/j.algal.2018.07.012

Priyanto, A., Doerksen, R., Chang, C., Sung, W., Widjanarko, S., Kusnadi, J., Lin, Y., Wang, T., \& Hsu, J. (2015). Screening, discovery, and characterization of angiotensin-I converting enzyme inhibitory peptides derived from proteolytic hydrolysate of bitter melon seed proteins. Journal of Proteomics, 128, 424-435. https://doi.org/DOI:10.1016/j.jprot.2015.08.018

Rao, A., Sarada, R., Baskaran, V., \& Ravishankar, G. (2006). Antioxidant activity of Botryococcus braunii extract elucidated in vitro models. Journal of Agricultural and Food Chemistry, 54(13), 4593-4599. https://doi.org/DOI: 10.1021/jf060799j

Safitri, N., Herawati, E., \& Hsu, J. (2017). Antioxidant activity of purified active peptide derived from Spirulina platensis enzymatic hydrolysates. Research Journal of Life Science, 4(2), 119-128.

https://doi.org/dx.doi.org/10.21776/ub.rjls.2017.004.0 2.5

Shih, Y., Chen, F., Wang, L., \& Hsu, J. (2019). Discovery and study of novel antihypertensive peptides derived from Cassia obtusifolia seeds. Journal of Agriculture and Food Chemistry, 67(28), 7810-7820. https://doi.org/DOI:10.1021/acs.jafc.9b01922

Tejano, L., Peralta, J., Yap, E., \& Chang, Y. (2019). Bioactivities of enzymatic protein hydrolysates derived from Chlorella sorokiniana. Food Science \& Nutrition, 7, 2381-2390. https://doi.org/doi.org/10.1002/fsn3.1097

Themaladze, G., \& Makhashvili, K. (2016). Climate change and photosynthesis. Annals of Agrarian Science, 14(2), 119126.https://doi.org/doi.org/10.1016/j.aasci.2016.05.01 2

Torres-Fuentes, C., Contreras, M. D. M., Recio, I., Alaiz, M., \& Vioque, J. (2015). Identification and characterization of 
antioxidant peptides from chickpea protein hydrolysates. Food Chemistry, 180, 194-202. https://doi.org/10.1016/j.foodchem.2015.02.046

Wu, L., Jiang, A., Jing, Y., Zheng, Y., \& Yan, Y. (2017). Antioxidant properties of protein hydrolysates from Douchi by membrane ultrafiltration. International Journal of Food Properties, 20(5), 997-1006. https://doi.org/doi.org/10.1080/10942912.2016.11926 44

Zhang, T., Li, Y., Miao, M., \& Jiang, B. (2011). Purification and characterization of a new antioxidant peptide from chickpea (Cicer arietium L) protein hydrolysates. Food Chemistry, 128, 28-33. https://doi.org/DOI:10.1016/j.foodchem.2011.02.072

Zhu, M.-Z., Li, N., Wang, Y.-T., Liu, N., Guo, M.-Q., Sun, B.-Q., Zhou, H., Liu, L., \& Wu, J.-L. (2017). Acid/Salt/pH
Gradient Improved Resolution and Sensitivity in Proteomics Study Using 2D SCX-RP LC-MS. J Proteome Res, 16(9), 3470-3475.

https://doi.org/DOI:10.1021/acs.jproteome.7b00443

Zielinski, D., Fraczyk, J., Debowski, M., Zielinski, M., Kaminski, Z. J., Kregiel, D., Jacob, C., \& Kolesinska, B. (2020). Biological activity of hydrophilic extract of Chlorella vulgaris grown on post-fermentation leachate from a biogas plant supplied with stillage and maize silage. Molecules, 25(8). https://doi.org/10.3390/molecules25081790

Zou, T. Bin, He, T. P., Li, H. Bin, Tang, H. W., \& Xia, E. Q. (2016). The structure-activity relationship of the antioxidant peptides from natural proteins. Molecules, 21(1), 1-14. https://doi.org/10.3390/molecules21010072 